BMJ Surgery, Interventions, $\&$ Health Technologies

\title{
How much is enough for total knee arthroplasty?
}

\author{
Caesar Wek, ${ }^{1}$ Tosan Okoro (D , ${ }^{2}$ Sebastian Tomescu, ${ }^{3} \mathrm{~J}$ Michael Paterson, ${ }^{4}$ \\ Bheeshma Ravi (D) ${ }^{3}$
}

To cite: Wek C, Okoro T, Tomescu S, et al. How much is enough for total knee arthroplasty? BMJ Surg Interv Health Technologies 2021;3:e000102. doi:10.1136/ bmjsit-2021-000102

Received 20 June 2021 Accepted 05 August 2021

\section{SLinked}

http://dx.doi.org/10.1136/ bmjsit-2021-000092

http://dx.doi.org/10.1136/ bmjsit-2020-000072

Check for updates

(c) Author(s) (or their employer(s)) 2021. Re-use permitted under CC BY-NC. No commercial re-use. See rights and permissions. Published by BMJ.

${ }^{1}$ Department of Trauma and Orthopaedics, King's College Hospital NHS Foundation Trust, London, UK

${ }^{2}$ Department of Arthroplasty, Robert Jones and Agnes Hunt Orthopaedic Hospital NHS

Foundation Trust, Oswestry, UK ${ }^{3}$ Division of Orthopedic Surgery, Sunnybrook Health Sciences Centre, Toronto, Ontario, Canada ${ }^{4}$ Institute for Clinical Evaluative Sciences, Toronto, Ontario, Canada

Correspondence to

Dr Tosan Okoro;

tosanwumi@hotmail.com
We welcome Professor Randsborg's suggestions that in addition to surgical volume, environmental factors such as institutional structures and patient demographics also impact on patient outcomes following total knee arthroplasty (TKA). However, we would argue that the true surgical volume is the most important factor when determining the risk of revision in TKA surgery, as demonstrated by our study. ${ }^{1}$ The findings in our study are echoed in the analysis by $\mathrm{Yu}$ et al, which concluded that from a number of outcomes evaluated, only surgical volume was associated with an increased risk of TKA 30-day readmission. ${ }^{2}$

While it is recognized that highly experienced orthopaedic surgeons may deliver excellent patient outcomes regardless of a minimum volume, evidence suggests that higher surgical volumes result in better patient outcomes. ${ }^{3}$ Data from Jeschke et al suggested that a minimum institutional threshold of 145 TKA procedures per annum would result in a reduction of revision rates. ${ }^{4}$ In the USA, reduced mortality rates were observed when surgeons performed greater than 15 cases per year and institutions performed greater than 85 cases. ${ }^{5}$ Further research by Wilson et al has sought to further define meaningful thresholds in the relationship between surgical volume and patient outcomes in TKA surgery. ${ }^{6}$ Their work reviewed various surgical procedure numbers among surgeons according to the revision rates from a database of 289976 knee arthroplasties. The data suggested that complication rates varied between surgeon procedure numbers of 0 and 12, 13 and 59, 60 and 145, and $>146$ cases per year. However, there was no change in revision rates once surgeon volume reached $>60$ cases per year. ${ }^{6}$ Furthermore, the methodology used by these studies either assumed a linear relationship between volume and outcomes or stratified volumes in the groups.
We agree that there is no accepted rigorous methodology for determining volume thresholds in arthroplasty, and various methodologies have been used in previous studies. Previous studies evaluating the relationship between surgeon volume and patient outcome indicate that this relationship is non-linear and that an optimal minimum volume should ideally be specified. However, there is currently no consensus among surgeons regarding the ideal value of this 'minimum number' of cases per annum. As suggested by Professor Randsborg, there may be variation in unit/institutional case match and complexity, so propensity matching was used in our study to adjust for differences in case complexity.

The statistical methodology used by this study was a restricted cubic spline regression (RCSR) method to evaluate the relationship between volume and patient outcome. RCSR is an adaptable tool used to model complex, non-linear relationships between continuous variables and a specific outcome. ${ }^{7}$ However, normal regression analyses assume a linear relationship between the predictor and outcome variables. This suggests that the impact of a rise in surgeon procedure volume would be similar if the increase in volume was from 10 to 30 cases/year, or from 210 to 230 cases/year. On the other hand, a spline does not make any assumptions of a linear relationship. It separates the relationship into smaller 'pieces', allowing non-linear portions. The non-linear relationship between surgeon procedure volume and the risk of revision surgery was examined to identify an inflection point, which could be used to categorize annual volume in a clinically meaningful way. In our study, the use of a spline also enabled the identification of a threshold of volume of 70 cases at which the greatest patient benefit is obtained. ${ }^{1}$ This RCSR method was also used by Chou et al in total hip arthroplasty and demonstrated that there was a minimum 
surgeon volume threshold of 15 cases per annum for reducing the 30-day unplanned readmission rates. ${ }^{8}$

As our paper concluded, surgeons who had performed less than 70 TKA procedures in the year prior to the patient's index TKA had a $31 \%$ increased risk of revision and an $18 \%$ increased risk of deep surgical infection requiring further surgery at 3 years of follow-up. ${ }^{1}$ In terms of what institutional/structural changes that we suggest armed with this knowledge, we use an example from the UK. In the UK, The Getting it Right First Time (GIRFT) report identified various challenges that were faced by UK orthopaedic departments to meet the arthroplasty need of an aging population. ${ }^{9}$ To address the challenges faced, the GIRFT report suggested several institutional changes, including the introduction of 'minimum numbers' of procedures and the centralization of complex procedures to institutions with appropriate expertise. Furthermore, low units are supported to increase caseloads, and patients should be empowered with unit and surgeon data to facilitate informed decision making.

Contributors CW, T0, JMP, ST and BR made substantial contributions to the conception or design of the work presented, drafting the work and revising it critically for important intellectual content; as well as final approval of the version to be published. All authors are in agreement to be accountable for all aspects of the work in ensuring that questions related to the accuracy or integrity of any part of the work are appropriately investigated and resolved.

Funding The authors have not declared a specific grant for this research from any funding agency in the public, commercial or not-for-profit sectors.

Competing interests None declared.

Patient consent for publication Not applicable.

Provenance and peer review Commissioned; internally peer reviewed.
Open access This is an open access article distributed in accordance with the Creative Commons Attribution Non Commercial (CC BY-NC 4.0) license, which permits others to distribute, remix, adapt, build upon this work non-commercially, and license their derivative works on different terms, provided the original work is properly cited, appropriate credit is given, any changes made indicated, and the use is non-commercial. See: http://creativecommons.org/licenses/by-nc/4.0/.

ORCID iDs

Tosan Okoro http://orcid.org/0000-0003-0432-0936

Bheeshma Ravi http://orcid.org/0000-0003-1829-6885

\section{REFERENCES}

1 Okoro T, Tomescu S, Paterson JM, et al. Analysis of the relationship between surgeon procedure volume and complications after total knee arthroplasty using a propensity-matched cohort study. BMJ Surg Interv Health Technol 2021;3:e000072.

2 Yu T-H, Chou Y-Y, Tung Y-C. Should we pay attention to surgeon or hospital volume in total knee arthroplasty? Evidence from a nationwide population-based study. PLoS One 2019;14:e0216667.

3 Hopgood P, Miles J, Carrington R. Minimum numbers. Knee 2020;27:1688-9.

4 Jeschke E, Citak M, Günster C, et al. Are TKAs performed in highvolume hospitals less likely to undergo revision than TKAs performed in low-volume hospitals? Clin Orthop Relat Res 2017;475:2669-74.

5 Hervey SL, Purves HR, Guller U, et al. Provider volume of total knee arthroplasties and patient outcomes in the HCUP-Nationwide inpatient sample. J Bone Joint Surg Am 2003;85:1775-83.

6 Wilson S, Marx RG, Pan T-J, et al. Meaningful thresholds for the volume-outcome relationship in total knee arthroplasty. J Bone Joint Surg Am 2016;98:1683-90.

7 Gauthier J, Wu QV, Gooley TA. Cubic splines to model relationships between continuous variables and outcomes: a guide for clinicians. Bone Marrow Transplant 2020;55:675-80.

8 Chou Y-Y, Tung Y-C. Optimal hospital and surgeon volume thresholds to improve 30-day readmission rates, costs, and length of stay for total hip replacement. J Arthroplasty 2019;34:1901-8.

9 Briggs T. A national review of adult elective orthopaedic services in England: getting it right first time. British orthopaedic association, 2015. Available: https://gettingitrightfirsttime.co.uk/wp-content/ uploads/2018/07/GIRFT-National-Report-Mar15-Web.pdf [Accessed 12 Jun 2021]. 